\title{
Synthesis of Chiral Schiff Base Metal Complex Inducing $C D$ and Elucidation of Structure of Adsorption on Surface of Gold Nanoparticles
}

\section{Minako Oshima, Minoru Matsuno, Tsutsumi Yuki, Sunaga Nobumitsu, Tomoyuki Haraguchi, Takashiro Akitsu*}

Department of Chemistry, Faculty of Science, Tokyo University of Science, Tokyo, Japan

Email: *akitsu@rs.kagu.tus.ac.jp

How to cite this paper: Oshima, M., Matsuno, M., Yuki, T., Nobumitsu, S., Haraguchi, T. and Akitsu, T. (2017) Synthesis of Chiral Schiff Base Metal Complex Inducing $\mathrm{CD}$ and Elucidation of Structure of Adsorption on Surface of Gold Nanoparticles. International Journal of Organic Chemistry, 7, 153-170.

https://doi.org/10.4236/ijoc.2017.72013

Received: May 19, 2017

Accepted: June 19, 2017

Published: June 22, 2017

Copyright $\odot 2017$ by authors and Scientific Research Publishing Inc. This work is licensed under the Creative Commons Attribution International License (CC BY 4.0).

http://creativecommons.org/licenses/by/4.0/

\begin{abstract}
We have prepared supramolecular systems of chiral Schiff base $\mathrm{Ni}(\mathrm{II}), \mathrm{Cu}(\mathrm{II})$, $\mathrm{Zn}$ (II) complexes and colloidal gold nanoparticles (AuNP) of $10 \mathrm{~nm}$ diameters. They demonstrated that direct adsorption of chiral Schiff base metal complex on the surface of AuNP owing to observation of clear induced CD spectra for the first time. We observed and discussed induced $\mathrm{CD}$ bands on AuNP from chiral Schiff base $\mathrm{Ni}(\mathrm{II}), \mathrm{Cu}(\mathrm{II}), \mathrm{Zn}(\mathrm{II})$ complexes.
\end{abstract}

\section{Keywords}

Chiral Schiff Base Metal Complex, Gold Nanoparticle

\section{Introduction}

Metal nanoparticles including gold nanoparticles have been a subject of research and applications in various fields because it has unique properties of surface plasmon resonance (SPR). There are many types of plasmonic concepts and applications. For example, the plasmon concept of the refractive index change is applied to the refractive index sensing [1] [2] and then the plasmon concept of hot electron transfer is conductivity and catalysis [3] [4] [5]. In addition, the plasmon concept of plasmon resonance energy transition is applied to SER and SERS [6] [7] [8] [9] [10] and then the plasmon concept of multiphoton photoluminescence is used to light-emitting systems [11], the concept of magnetic plasmon propagation is used to plasmonic antiferromagnetism [12]. The concept of chiral dipole-dipole coupling has been applied to optically active plasmon [13] [14] [15] [16].

Recently, induced CD on metal nanoparticles from chiral additive molecules 
including biomolecules [17] have been attracted much attention in the field of nano-chirality [18] [19] [20], which are beyond conventional framework of chirality of micro-matters [21]. In principle, intensity of induced CD increases or decreases depending on parallel and perpendicular arrangement of transition moments of metal nanoparticles and chiral additive molecules, respectively [20]. However, actual situation of supramolecular systems of metal nanoparticles and chiral additives are more complicated. Although some metal nanoparticles exhibit chiroptical properties [22], addition of chiral additives onto achiral metal nanoparticles may be significant due to their potential applications for chiral catalysts [23]. Elucidation of the adsorption structure of the gold and the chiral additives and its effects are also an important concern (Scheme 1) [24] [25] [26].

To date we have reported induced CD due to chiral Schiff base metal complexes onto various materials, for example, achiral Schiff base metal complexes [27], achiral ferrocene [28], metallodendrimers and metal nanoclusters made in them [29] [30], nanoparticles of metal semiconductors [31]. Some chiral Schiff base complexes have large electronic transition dipole moment, but less induced $\mathrm{CD}$ can be observed experimentally. As for copper nanoparticles made in metallodendrimers [31] [32] disagreement between experimental results [32] and theoretical dipole moment [33] may be attributed to molecular recognition of chiral additives onto particle surfaces [34]. Moreover, some chiral metal complexes exhibited weaken induced CD [35] because of arrangement of dipole molecules of both species.

Practically, chiral AuNP catalysts will be expected as candidate materials for organic silanol reaction that has been used as an attractive nucleophile agent mainly. There may be three reaction acts as nucleophile agent of silanol. The first is used as a bond formation or base by nucleophilic reaction of silanol oxygen. The second is a specific reaction of the neighboring functional groups that use the interaction between the hydroxyl group and a metal compound. And the third is a molecule conversion utilizing specific reactivity of the silicon-bonded carbon one based on the presence of silanol hydroxyl groups. In this way, silanol

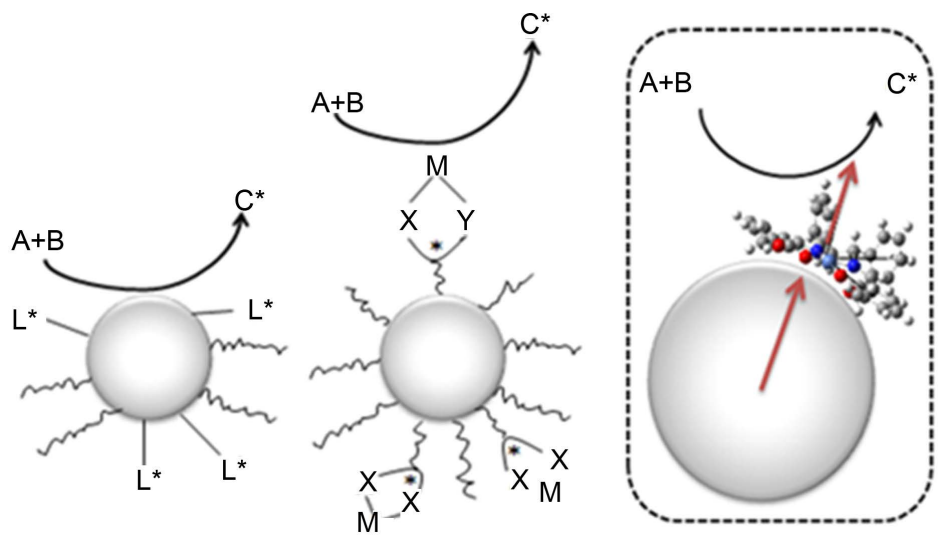

Scheme 1. Concept of chiral catalysis including AuNP: [Left] heterogeneous type having chiral ligands [23], [Middle] chiral homogenous type linked by AuNP binder [23], [Right] homogeneous type having chiral ligands (present). 
might be attractive as a nucleophile agent. Moreover, the expected co-product must be hydrogen gas in the synthesis process, which is ideal in terms of the environment.

Herein we have successfully observed considerably intense induced CD demonstrated onto AuNP in plasmon region due to chiral Schiff base $\mathrm{Ni}(\mathrm{II}), \mathrm{Cu}(\mathrm{II})$, and $\mathrm{Zn}(\mathrm{II})$ complexes (compound 1a-1c) for the first time. With a different ligand complex of by synthesizing eleven compounds (compound $2 \mathbf{a}-\mathbf{5 c}$ ) including compound 1a-1c (Scheme 2), we compared the differences of the induced CD. Using a TD-DFT we predicted adsorption structure.

\section{Methods and Experimental Details}

\subsection{Preparation of Complexes}

We prepared eleven compounds has various ligands. Compounds $1 \mathrm{a}, 1 \mathbf{b}$ and $1 \mathrm{c}$ were prepared according to the literature procedure [36]. Compounds $\mathbf{2 a}$ and $\mathbf{2 b}$ were prepared according to the literature procedure [37]. Compound 4 was prepared according to the literature procedure [38].

Preparation of $2 \mathrm{c}$ : To a solution of salicylaldehyde $(0.244 \mathrm{~g}, 2.00 \mathrm{mmol})$ dissolved in methanol $(40 \mathrm{~mL}),(1 \mathrm{R}, 2 \mathrm{R})-(+)-1,2$-Diphenylethylenediamine $(0.212 \mathrm{~g}$, $1.00 \mathrm{mmol}$ ) was added and stirred at $313 \mathrm{~K}$ for $2 \mathrm{~h}$ to give yellow solution of ligand. Zinc(II) acetate dehydrate $(0.220 \mathrm{~g}, 1.00 \mathrm{mmol})$ was added to the resulting solution and stirring at $313 \mathrm{~K}$ for $2 \mathrm{~h}$ to give yellow solution of the complex. After cooling the solution, this yellow compound was filtered. Yield $0.302 \mathrm{~g}$ (61.4\%). Anal. Found: C, 56.27; H, 5.25; N, 54.53\%. Calc. for $\mathrm{C}_{28} \mathrm{H}_{22} \mathrm{~N}_{2} \mathrm{O}_{2} \mathrm{Zn}$ : C, 59.15; H, 5.42; N, 4.18\%. IR ( $\mathrm{KBr}(\mathrm{cm}-1)): 1627(\mathrm{C}=\mathrm{N})$. UV-Vis (diffuse reflectance) peak/nm; 391. CD (KBr) peak/nm; 383.

Preparation of 3: To a solution of 2,3-Dihydroxybenzaldehyde (0.276 g, 2.00 $\mathrm{mmol})$ dissolved in methanol $(40 \mathrm{~mL}),(1 R, 2 R)-(+)-1,2$-Diphenylethylenediamine $(0.212 \mathrm{~g}, 1.00 \mathrm{mmol})$ was added and stirred at $313 \mathrm{~K}$ for $2 \mathrm{~h}$ to give brown solution of ligand. Copper(II) acetate monohydrate $(0.200 \mathrm{~g}, 1.00 \mathrm{mmol})$ was added to the resulting solution and stirring at $313 \mathrm{~K}$ for $2 \mathrm{~h}$ to give brown solution of the complex. After cooling the solution, this brown compound was fil

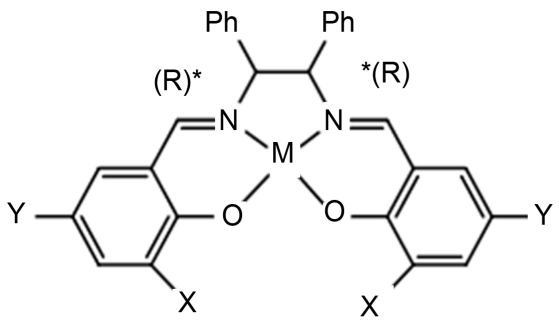

$\begin{array}{cccc} & \mathrm{X} & \mathrm{Y} & \mathrm{M} \\ \text { 1a } & \mathrm{CH}_{3} \mathrm{O}- & \mathrm{CH}_{3} \mathrm{O}- & \mathrm{Ni} \\ \text { 1b } & \mathrm{CH}_{3} \mathrm{O}- & \mathrm{CH}_{3} \mathrm{O}- & \mathrm{Cu} \\ \text { 1c } & \mathrm{CH}_{3} \mathrm{O}- & \mathrm{CH}_{3} \mathrm{O}- & \mathrm{Zn} \\ 2 \mathrm{a} & \mathrm{H}- & \mathrm{H}- & \mathrm{Ni} \\ 2 \mathrm{~b} & \mathrm{H}- & \mathrm{H}- & \mathrm{Cu} \\ 2 \mathrm{C} & \mathrm{H}- & \mathrm{H}- & \mathrm{Zn} \\ 3 & \mathrm{OH}- & \mathrm{OH}- & \mathrm{Cu} \\ 4 & \mathrm{tBu}- & \mathrm{tBu}- & \mathrm{Cu} \\ 5 \mathrm{~B} & \mathrm{Br}- & \mathrm{Br}- & \mathrm{Ni} \\ 5 \mathrm{~b} & \mathrm{Br}- & \mathrm{Br}- & \mathrm{Cu} \\ 5 \mathrm{c} & \mathrm{Br}- & \mathrm{Br}- & \mathrm{Zn}\end{array}$

Scheme 2. Chemical Structures of eleven compounds. 
tered. Yield $0.412 \mathrm{~g}$ (77.7\%). Anal. Found: C, 65.59; H, 4.61; N, 5.37\%. Calc. for $\mathrm{C}_{28} \mathrm{H}_{22} \mathrm{~N}_{2} \mathrm{O}_{4} \mathrm{Cu}: \mathrm{C}, 65.42 ; \mathrm{H}, 4.31 ; \mathrm{N}, 5.45 \%$. IR $\left(\mathrm{KBr}\left(\mathrm{cm}^{-1}\right)\right): 1617(\mathrm{C}=\mathrm{N}), 3417$ (OH). UV-Vis (diffuse reflectance) peak/nm; 446, 574. CD (KBr) peak/nm; 434, 610.

Preparation of $5 \mathrm{a}$ : To a solution of 3,5-Dibromosalicylaldehyde $(0.560 \mathrm{~g}, 2.00$ $\mathrm{mmol})$ dissolved in methanol $(40 \mathrm{~mL}),(1 \mathrm{R}, 2 \mathrm{R})-(+)-1,2-$ Diphenylethylenediamine $(0.2122 \mathrm{~g}, 1.00 \mathrm{mmol})$ was added and stirred at $313 \mathrm{~K}$ for $2 \mathrm{~h}$ to give yellow solution of ligand. Nickel (II) acetate tetrahydrate $(0.249 \mathrm{~g}, 1.00 \mathrm{mmol})$ was added to the resulting solution and stirring at $313 \mathrm{~K}$ for $2 \mathrm{~h}$ to give orange solution of the complex. After cooling the solution, this orange compound was filtered. Yield $0.695 \mathrm{~g}$ (86.8\%). Anal. Found: C, 42.76; H, 2.36; N, 3.44\%. Calc. for $\mathrm{C}_{28} \mathrm{H}_{18} \mathrm{Br}_{4} \mathrm{~N}_{2} \mathrm{O}_{2} \mathrm{Ni}: \mathrm{C}, 42.42 ; \mathrm{H}, 2.29 ; \mathrm{N}, 3.53 \%$. IR $\left(\mathrm{KBr}\left(\mathrm{cm}^{-1}\right)\right): 1620(\mathrm{C}=\mathrm{N})$. UV-Vis (diffuse reflectance)/nm ; 430, 573. CD (KBr) peak/nm ; 409, 572.

Preparation of $5 \mathrm{~b}$ : To a solution of 3,5-Dibromosalicylaldehyde $(0.560 \mathrm{~g}$, $2.00 \mathrm{mmol})$ dissolved in methanol $(40 \mathrm{~mL}),(1 \mathrm{R}, 2 \mathrm{R})-(+)-1,2$-Diphenylethylenediamine $(0.212 \mathrm{~g}, 1.00 \mathrm{mmol})$ was added and stirred at $313 \mathrm{~K}$ for $2 \mathrm{~h}$ to give yellow solution of ligand. Copper(II) acetate monohydrate(0.200 g, $1.00 \mathrm{mmol})$ was added to the resulting solution and stirring at $313 \mathrm{~K}$ for $2 \mathrm{~h}$ to give green solution of the complex. After cooling the solution, this green compound was filtered. Yield $0.725 \mathrm{~g}$ (90.9\%). Anal. Found: C, 42.06; H, 2.27; N, 3.43\%. Calc. for $\mathrm{C}_{28} \mathrm{H}_{18} \mathrm{Br}_{4} \mathrm{~N}_{2} \mathrm{O}_{2} \mathrm{Cu}: \mathrm{C}, 42.16 ; \mathrm{H}, 2.27 ; \mathrm{N}, 3.51 \%$. IR $\left(\mathrm{KBr}\left(\mathrm{cm}^{-1}\right)\right): 1623(\mathrm{C}=\mathrm{N})$. UV-Vis (diffuse reflectance) peak/nm; 399, 582. $\mathrm{CD}(\mathrm{KBr})$ peak/nm ; 379, 575.

Preparation of $5 \mathrm{c}$ : To a solution of 3,5-Dibromosalicylaldehyde $(0.560 \mathrm{~g}, 2.00$ mmol dissolved in methanol (40 mL), (1R,2R)-(+)-1,2-Diphenylethylenediamine $(0.212 \mathrm{~g}, 1.00 \mathrm{mmol})$ was added and stirred at $313 \mathrm{~K}$ for $2 \mathrm{~h}$ to give yellow solution of ligand. Zinc(II) acetate dihydrate $(0.220 \mathrm{~g}, 1.00 \mathrm{mmol})$ was added to the resulting solution and stirring at $313 \mathrm{~K}$ for $2 \mathrm{~h}$ to give yellow solution of the complex. After cooling the solution, this yellow compound was filtered. Yield $0.692 \mathrm{~g}$ (86.6\%). Anal. Found: C, 42.01; H, 2.02; N, 3.33\%. Calc. for $\mathrm{C}_{28} \mathrm{H}_{18} \mathrm{Br}_{4} \mathrm{~N}_{2} \mathrm{O}_{2} \mathrm{Zn}$ : C, 42.07; H, 2.27; N, 3.50\%. IR $\left(\mathrm{KBr}\left(\mathrm{cm}^{-1}\right)\right): 1629(\mathrm{C}=\mathrm{N})$. UVVis (diffuse reflectance) peak/nm; 404. CD (KBr) peak/nm; 401.

\subsection{Preparation of AuNP and Complexes of Composite Solution}

AuNP (10 nm) were purchased from Funakoshi (BMGC10) and used without further purification. Spectral measurements were performed as $0.005 \mathrm{mM}-0.1$ $\mathrm{mM}$ solutions for chiral metal complexes and the most suitable 1:1 (v/v) solutions for mixed solutions of chiral metal complexes and AuNP. The experimental conditions were investigated widely.

\subsection{Measurements}

Electronic spectra were measured on a JASCO V-570 spectrophotometer in the range of $900-200 \mathrm{~nm}$ at $298 \mathrm{~K}$. Circular dichroism (CD) spectra were measured on a JASCO J-725 spectropolarimeter in the range of $800-200 \mathrm{~nm}$ at $298 \mathrm{~K}$. 


\subsection{Calculations}

Geometry optimization and normal vibration analysis are computed using DFT with B3LYP functional, Lanl2dz for $\mathrm{Cu}, \mathrm{Ni}$, and $\mathrm{Zn}$ and $6-31+\mathrm{G}(\mathrm{d})$ basis set for $\mathrm{H}, \mathrm{C}, \mathrm{N}, \mathrm{O}$ and $\mathrm{Br}$ in the GAUSSIAN 03 program package [39]. In addition, transition electric dipole moment and excitation energies are calculated using TD-DFT with B3LYP functional, Lanl2dz for $\mathrm{Cu}, \mathrm{Ni}$, and $\mathrm{Zn}$ and $6-31+\mathrm{G}(\mathrm{d})$ basis set for $\mathrm{H}, \mathrm{C}, \mathrm{N}$ and $\mathrm{O}$. For comparison, transition electric dipole moment and excitation energies are also calculated using ZINDO. As ability of induced CD, dipole moments of molecules were calculated by TD-DFT.

\subsection{Rietveld Structural Analysis}

The powder X-ray diffraction (XRD) pattern of complexes 2c (Figure 1) were collected at $298 \mathrm{~K}$ on Rigaku Smart lab at the University of Tokyo. A capillary was packed with a powder sample (whose quality was confirmed characteristic peaks around 7, 8, and 17 degree) and measurement was performed. Intensity data were collected on a Rigaku Smart lab with graphite monochromated $\mathrm{Cu} \mathrm{Ka}$ radiation (1.54184 $\AA$ ). Structural analysis by the Rietveld method [40] was carried out using PDXL2 ver.2.2.1.0 (Rigaku Corporation).

\subsection{X-Ray Crystallography}

Single crystals were glued on top of a glass fiber and coated with a thin layer of epoxy resin to measure the diffraction data. Intensity data were collected on a Bruker APEX2 CCD diffractometer with graphite monochromated Mo Ka radiation $(k=0.71073 \AA$ ). Data analysis was conducted using the SAINT program package. The structures were solved by direct methods with SHELXS-97 [41], expanded by Fourier techniques and refined by the full-matrix least-squares method based on $\mathrm{F}^{2}$ with the program SHELXL-97 [41]. An empirical absorption correction was applied in the program SADABS. All non-hydrogen atoms were readily located and refined by anisotropic thermal parameters. All hydrogen atoms were located at geometrically calculated positions and refined using riding models.

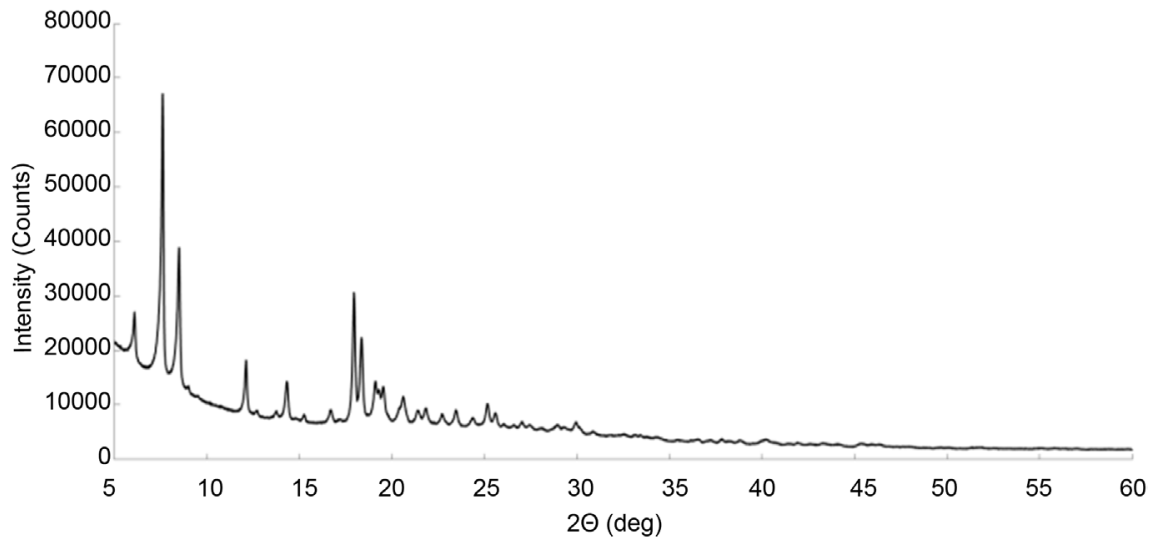

Figure 1. Powder X-ray diffraction patterns of 2c. 


\section{Results and Discussion}

\subsection{CD spectra and UV Spectra Results}

Figures 2-4 depict electronic and CD spectra of hybrid system of AuNP and 1a, $1 \mathrm{~b}$ and $1 \mathrm{c}$, respectively. Pure AuNP $(10 \mathrm{~nm})$ showed surface plasmon band at around $530 \mathrm{~nm}$ without distinct $\mathrm{CD}$ bands. On the other hand, Pure compound $1 \mathrm{a}, 1 \mathrm{~b}$ and $1 \mathrm{c}$ exhibited predominant absorption bands at 400,380 , and $380 \mathrm{~nm}$, respectively, and predominant $\mathrm{CD}$ peaks at $400 \mathrm{~nm}$. It should be noted that mixed solutions (namely hybrid systems) of each metal complex and AuNP (10 $\mathrm{nm}$ ) exhibited predominantly induced CD bands at about $600 \mathrm{~nm}$. The bands are close to surface plasmon band of pure AuNP and no CD peak could be observed as neither pure AuNP nor pure $\mathbf{1 a}, \mathbf{1 b}$ and $\mathbf{1} \mathrm{c}$. It should also be noted that the intensity of induced CD peaks were clearly increased for the first time among our studies using chiral Schiff base additives, which is distinctly different from weakly induced or negatively induced ones [32]. Interestingly, additional and characteristic (chiro) optical absorption resulting from supramolecular assemblies could be observed for the present system.

Induced $C D$ was observed in the same manner about $4,5 a, 5 b$ and $5 c$. Induced $\mathrm{CD}$ was not observed about $\mathbf{2 a}, \mathbf{2 b}, \mathbf{2 c}$ and $\mathbf{3}$. From the existing theory [20], it considered for the dipole moment of the gold nanoparticles and the complexes is a vertical. The supporting information shows the results of other compounds.
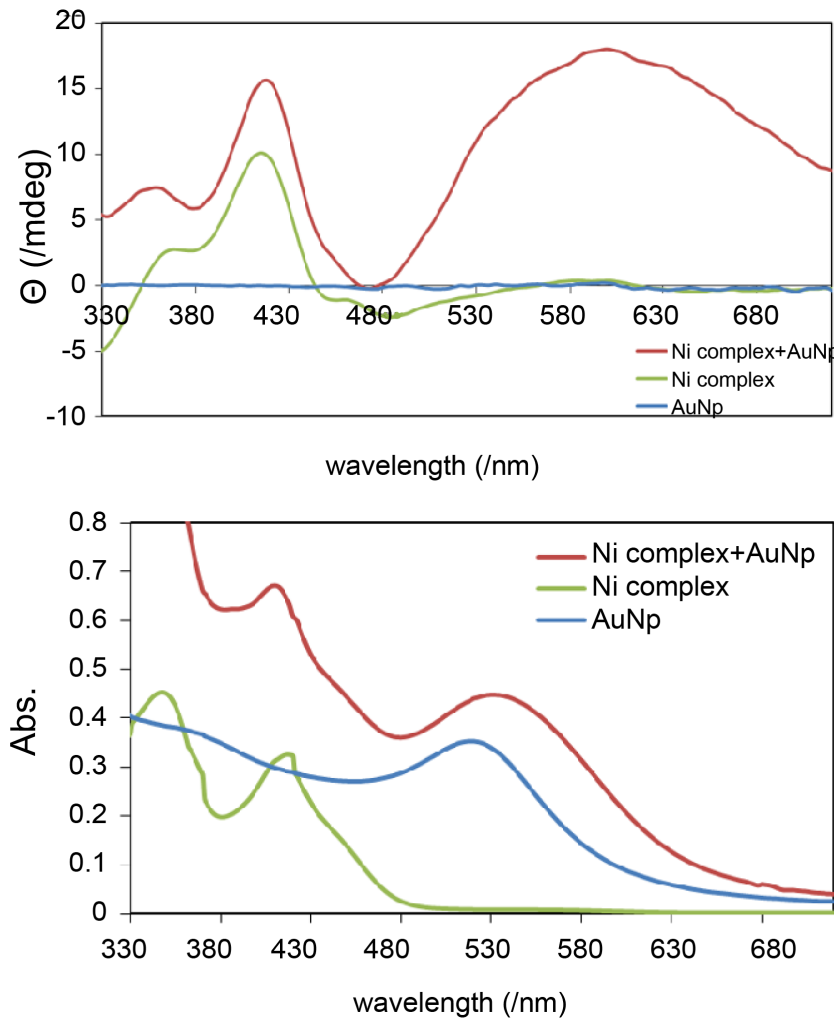

Figure 2. CD and electronic spectra of the systems of AuNP and 1a. Plasmon-induced is observed to $550 \mathrm{~nm}$. 


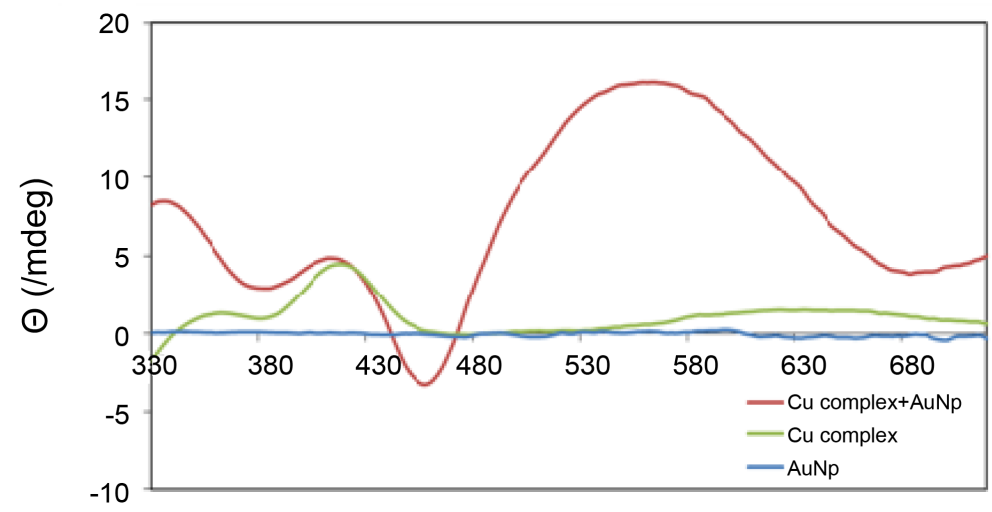

wavelength $(/ \mathrm{nm})$

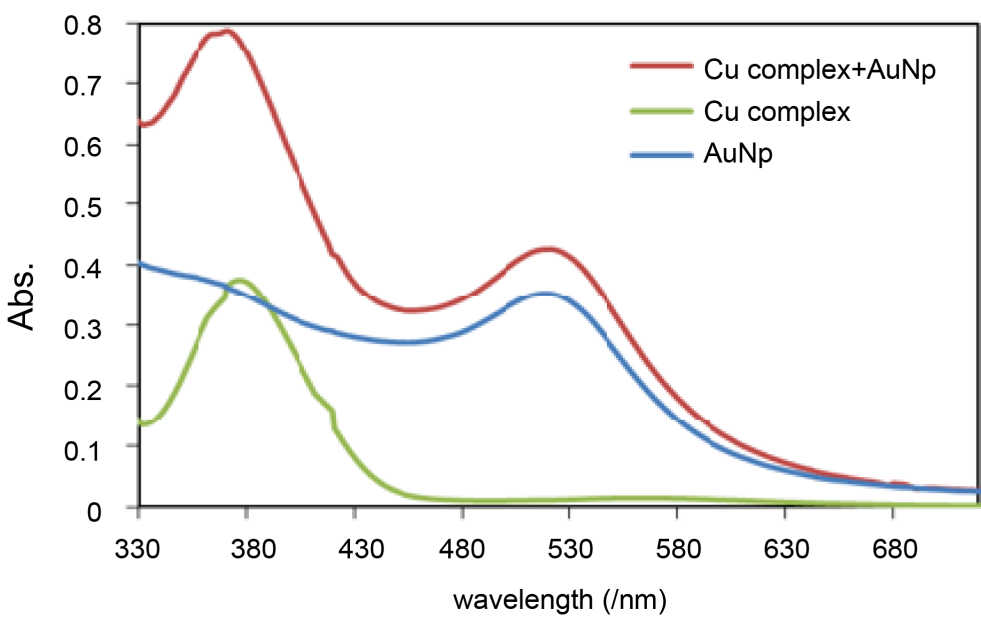

Figure 3. CD and electronic spectra of the systems of AuNP and 1b. Plasmon-induced is observed to $550 \mathrm{~nm}$.

\subsection{TD-DFT Calculation and Expectation of Adsorption Structure}

Figure 9 (left) shows calculated electric dipole moments (for optimized structures) of the chiral metal complexes, which are orientated in the direction of center of two phenyl groups regardless of metal centers. Furthermore, optimized structures of the complexes suggested that square planar coordination geometry and conformation of organic ligands are suitable for adsorption onto the surface of AuNP by methoxy groups. According to parallel arrangement of electric transition dipole moment to enhance induced $\mathrm{CD}$ band associated with surface plasmon band based on theoretical study [20], electric supramolecular hybrid systems may be proposed in Figure 5 (right).

\subsection{Structural Description}

\subsubsection{Structure Description of 2c}

The crystallographic data and selected bond lengths for $2 \mathrm{c}$ are listed in Table 1 and Table 2, respectively. The crystal of $2 c$ crystallized in the orthorhombic (chiral and non-polar) space group $P 2_{1} 2_{1} 2_{1}$ with $Z=2$. This complex is a strain square-planar complex these central metal is zinc. Its packing shows in which 

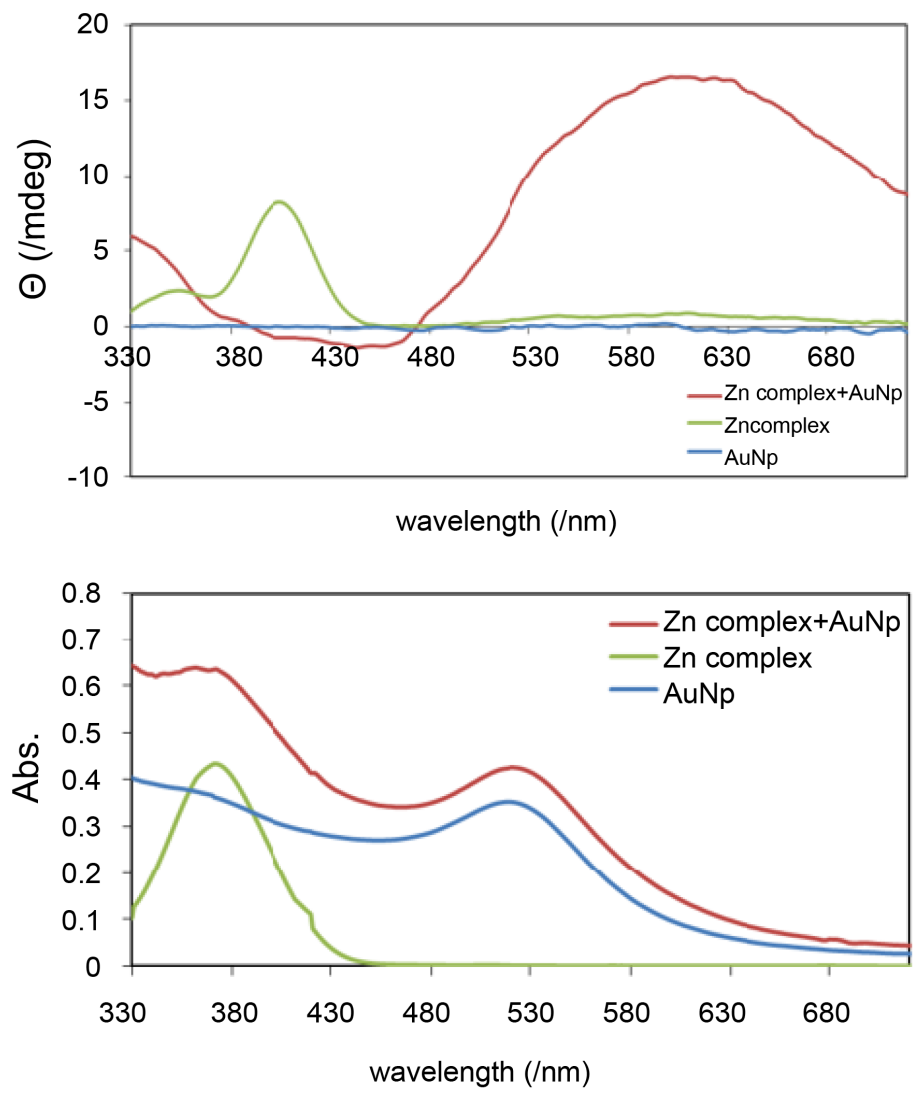

Figure 4. CD and electronic spectra of the systems of AuNP and 1c. Plasmon-induced is observed to $550 \mathrm{~nm}$.

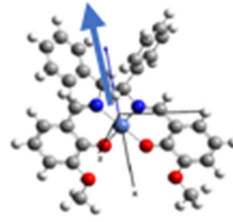

$\mathrm{Ni}$

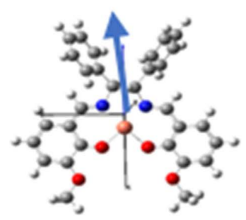

$\mathrm{Cu}$

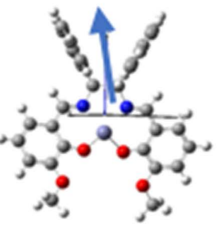

$\mathrm{Zn}$

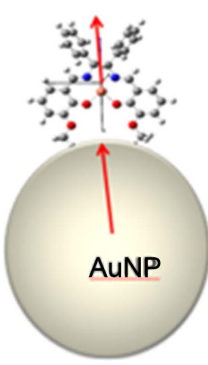

AuNP

Figure 5. [Left] Calculated electric dipole moments (blue arrows in similar direction with slightly different magnitudes) for compound $1 \mathrm{a}, 1 \mathrm{~b}$ and $1 \mathrm{c}$ of optimized structures. [Right] Proposed arrangement of supramolecular hybrid systems of chiral complex and AuNP.

planar ligands not to overlap (Figure 6, Figure 7). The results of calculation and results of X-ray structure analysis were compared. Surroundings of $\mathrm{Zn}$ are distorted flat type, which is different from the optimized structure adopting the plan type arrangement. Both of the phenyl groups were arranged in an overlapping manner, and it was almost the same arrangement as the optimized structure.

\subsubsection{Structure Description of 3}

The crystallographic data and selected bond lengths for 3 are listed in Table 3 
Table 1. Crystal data and structure refinement (Rietveld with PDXL2) for 2c.

\begin{tabular}{cc}
\hline Empirical formula & $\mathrm{C}_{28} \mathrm{H}_{22} \mathrm{~N}_{2} \mathrm{O}_{2} \mathrm{Zn}$ \\
\hline Crystal system & orthorhombic \\
Space group & $\mathrm{P} 212121$ \\
$\mathrm{Z}$ & 4 \\
$\mathrm{a}(\AA)$ & $11.616(3)$ \\
$\mathrm{b}(\AA)$ & $23.198(8)$ \\
$\mathrm{c}(\AA)$ & $9.379(3)$ \\
$\mathrm{V}(\AA)$ & $2527.4(13)$ \\
$\rho \mathrm{A} a \mathrm{c}\left(\mathrm{g} / \mathrm{cm}^{3}\right)$ & 1.270 \\
$\mu\left(\mathrm{mm}^{-1}\right)$ & 1.5413 \\
$\mathrm{~F}(000)$ & 1000.0 \\
$\mathrm{Rwp}(\%)$ & 8.37 \\
\hline
\end{tabular}

Table 2. Selected bond lengths $[\AA]]$ and angles $\left[{ }^{\circ}\right]$ for $2 \mathrm{c}$.

\begin{tabular}{cccc}
\hline Zn1-N1 & $2.102(4)$ & O1-Zn1-O2 & $107.72(2)$ \\
\hline Zn1-O1 & $1.951(5)$ & O1-Zn1-N1 & $153.22(4)$ \\
Zn1-N2 & $2.102(3)$ & O1-Zn1-N2 & $90.79(2)$ \\
Zn1-O2 & $1.951(4)$ & O2-Zn1-N1 & $90.79(2)$ \\
& & O2-Zn1-N2 & $153.22(5)$ \\
& & N1-Zn1-N2 & $79.55(19)$ \\
\hline
\end{tabular}

Table 3. Crystal data and structure refinement for 3.

\begin{tabular}{cc}
\hline Empirical formula & $\mathrm{C}_{28} \mathrm{H}_{22} \mathrm{~N}_{2} \mathrm{O}_{4} \mathrm{Cu}$ \\
\hline Crystal system & monoclinic \\
Space group & $\mathrm{C} 2$ \\
$\mathrm{Z}$ & 4 \\
$\mathrm{a}(\AA)$ & $16.703(8)$ \\
$\mathrm{b}(\AA)$ & $18.783(8)$ \\
$\mathrm{c}(\AA)$ & $8.056(4)$ \\
$\beta\left({ }^{\circ}\right)$ & $93.856(7)$ \\
$\mathrm{V}(\AA \AA)$ & $2521.7(19)$ \\
$\rho \mathrm{Acalc}\left(\mathrm{g} / \mathrm{cm}^{3}\right)$ & 1.396 \\
$\mu\left(\mathrm{mm}^{-1}\right)$ & 0.907 \\
$\mathrm{~F}(000)$ & 1092.0 \\
$\mathrm{Goodness}$ of fit & 1.786 \\
$\mathrm{R} 1[\mathrm{I}>2 \sigma(\mathrm{I})]$ & 0.0863 \\
$\mathrm{wR} 2$ & 0.2462 \\
\hline & \\
\hline &
\end{tabular}




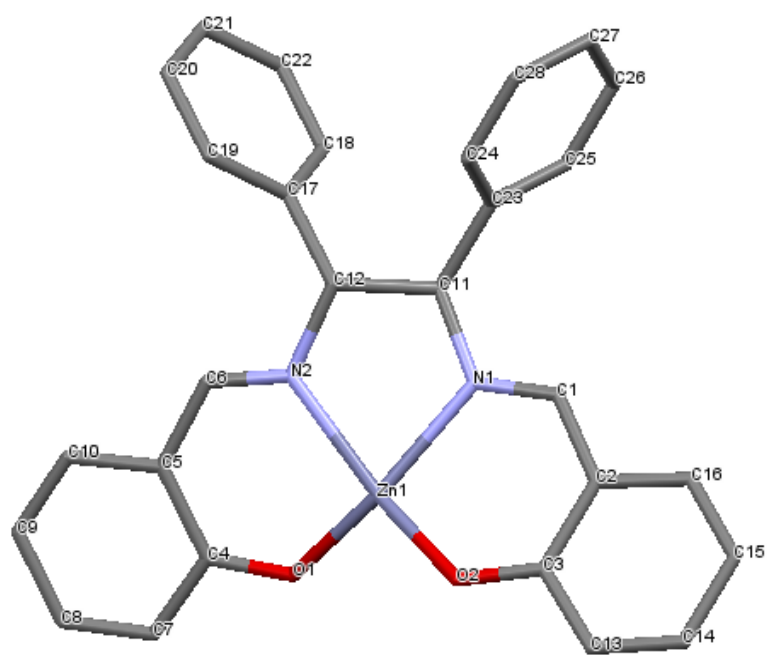

Figure 6. Crystal structure of $2 c$ showing selected atom labeling scheme. Hydrogen atoms are omitted for clarity.

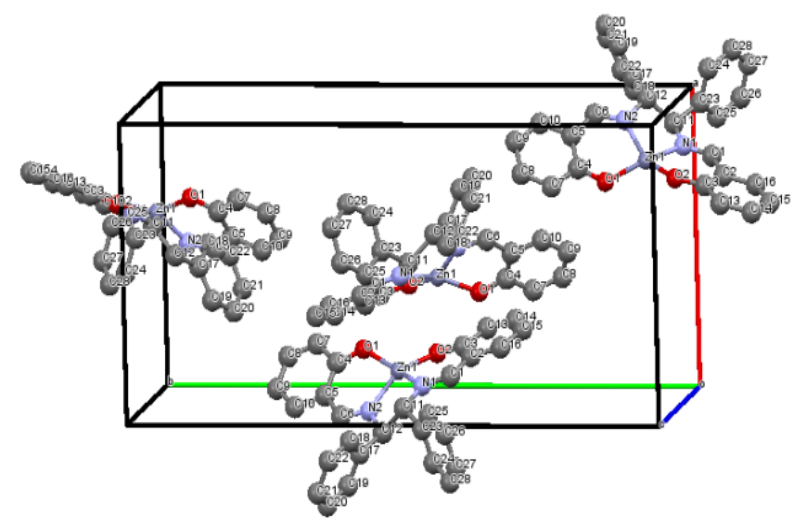

Figure 7. A perspective view of the packing of $2 \mathrm{c}$.

and Table 4, respectively. The crystal of 3 crystallized in the monoclinic (chiral and non-polar) space group $C 2$ with $\mathrm{Z}=4$. This complex is a square-planar complex these central metal is copper (Figure 8). Its packing shows in which planar ligands overlap in the $c$ axis direction (Figure 9). The results of calculation and results of X-ray structure analysis were compared. Independent two molecules of the asymmetric unit have the same structure, the periphery of the copper is a planar type, and both phenyl groups are arranged in an overlapping arrangement. The length from the adsorbed hydroxyl group was almost the same as the optimized structure $(0.9773 \mathrm{~nm})$.

\section{Conclusion}

We have observed significantly enhanced induced CD bands on AuNP for chiral Schiff base complexes and estimated their molecular arrangement based on parallel transition dipole moment. We have observed significantly enhanced induced CD bands on AuNP due to chiral Schiff base complexes and estimated their molecular arrangement based on parallel transition dipole moment. From 


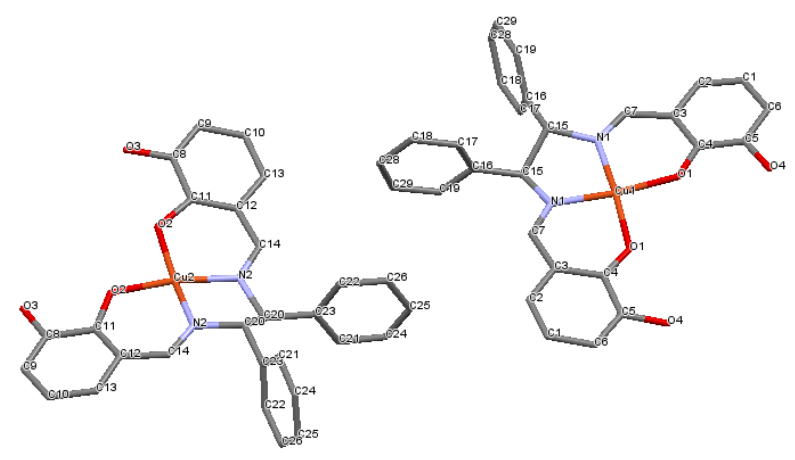

Figure 8. Crystal structure of 3 showing selected atom labeling scheme. Hydrogen atoms are omitted for clarity.

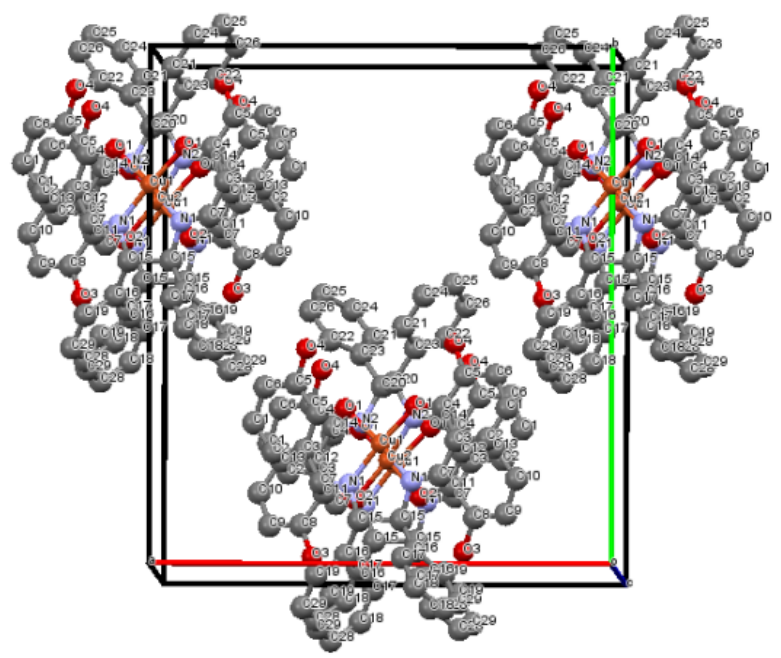

Figure 9. A perspective view of the packing of 3.

Table 4. Selected bond lengths $[\AA]$ and angles $\left[{ }^{\circ}\right]$ for 3 .

\begin{tabular}{llll}
\hline Cu1-N1 & $1.918(13)$ & O1-Cu1-O1a & $91.8(6)$ \\
\hline Cu1-O1 & $1.899(10)$ & O1-Cu1-N1 & $92.1(4)$ \\
Cu1-N1a & $1.918(13)$ & O1-Cu1-N1a & $174.0(5)$ \\
Cu1-O1a & $1.899(10)$ & O1a-Cu1-N1 & $174.0(5)$ \\
Cu2-N2 & $1.955(12)$ & O1a-Cu1-N1a & $92.1(4)$ \\
Cu2-O2 & $1.907(10)$ & N1-Cu1-N1a & $84.3(7)$ \\
Cu2-N2a & $1.955(12)$ & O2-Cu2-O2b & $87.0(6)$ \\
Cu2-O2a & $1.907(10)$ & O2-Cu2-N2 & $95.4(4)$ \\
& & O2b-Cu2-N2 & $167.4(4)$ \\
& & O2-Cu2-N2b & $167.4(4)$ \\
& & O2b-Cu2-N2b & $95.4(4)$ \\
& & N2-Cu2-N2b & $85.0(7)$ \\
\hline
\end{tabular}

XPS measurement, we found the complex is present in the Au substrate surface in the form of a complex. From the STM measurement, the complex which has 
been observed induced $\mathrm{CD}$ is adsorbed standing on the Au surface. On the other hand, the complex which has not been observed induced CD is adsorbed on the $\mathrm{Au}$ surface in the state complex which doesn't have central metal. The proposed supramolecular structures have potential application as new type of chiral AuNP catalysts possessing merits of both heterogenous (AuNP with chiral ligands) and homogenous (AuNP supported chiral metal complexes) ones on the surface (Scheme 1). Further investigation about chiral catalytic functions is in progress now. However, it should be noted here that merely small amount of bubbles was confirmed from the Au substrate surface during the preliminary reaction aiming at applications.

\section{Acknowledgements}

This work was partly performed under the Cooperative Research Program of "Network Joint Research Centre for Materials and Devices". The authors thank Profs. Kenji Hara and Toshikazu Kawaguchi (Hokkaido University) for preliminary discussion for surface and catalysis chemistry (Supplementary File).

\section{References}

[1] Liz-Marzán, L.M. (2004) Formation and Color. Nanometals. Mater. Today, 7, 2631. https://doi.org/10.1016/S1369-7021(04)00080-X

[2] Chen, H., Ming, T., Zhao, L., Wang, F., Sun, L.D., Wang, J. and Yan, C.H. (2010) Plasmon-Molecule Interactions. Nano Today, 5, 494-505. https://doi.org/10.1016/j.nantod.2010.08.009

[3] Knight, M.W., Sobhani, H., Nordlander, P. and Halas, N.J. (2011) Photodetection with Active Optical Antennas. Science, 332, 702-704. https://doi.org/10.1126/science.1203056

[4] Christopher, P., Xin, H. and Linic, S. (2011) Visible-Light-Enhanced Catalytic Oxidation Reactions on Plasmonic Silver Nanostructures. Nature Chemistry, 3, $467-$ 472. https://doi.org/10.1038/nchem.1032

[5] Wang, C.L. and Didier, A. (2014) Nanogold Plasmonic Photocatalysis for Organic Synthesis and Clean Energy Conversion. Chemical Society Reviews, 43, 7188-7216. https://doi.org/10.1039/C4CS00145A

[6] Lakowicz, J.R., Ray, K., Chowdhury, M., Szmacinski, H., Fu, Y., Zhang, J. and Nowaczyk, K. (2008) Plasmon-Controlled Fluorescence: A New Paradigm in Fluorescence Spectroscopy. Analyst, 133, 1308-1346. https://doi.org/10.1039/b802918k

[7] Nie, S. and Emory, S.R. (1997) Probing Single Molecules and Single Nanoparticles by Surface-Enhanced Raman Scattering. Science, 275, 1102-1106. https://doi.org/10.1126/science.275.5303.1102

[8] Xu, L., Kuang, H., Wang, L. and Xu, C. (2011) Gold Nanorod Ensembles as Artificial Molecules for Applications in Sensors. Journal of Materials Chemistry, 21, 16759-16782. https://doi.org/10.1039/c1jm11905b

[9] Lee, A., Andrade, G.F.S., Ahmed, A., Souza, M.L., Coombs, N., Tumarkin, E., Liu, K., Gordon, R., Brolo, A.G. and Kumacheva, E. (2011) Probing Dynamic Generation of Hot-Spots in Self-Assembled Chains of Gold Nanorods by Surface-Enhanced Raman Scattering. Journal of the American Chemical Society, 133, 7563-7570. https://doi.org/10.1021/ja2015179

[10] Choulis, S.A., Mathai, M.K. and Choong, V.E. (2006) Influence of Metallic Nano- 
particles on the Performance of Organic Electrophosphorescence Devices. Applied Physics Letters, 88, 213503. https://doi.org/10.1063/1.2200285

[11] Huang, J.S., Kern, J., Geisler, P., Weinmann, P., Kamp, M., Forchel, A., Biagioni, P. and Hecht, B. (2010) Mode Imaging and Selection in Strongly Coupled Nanoantennas. Nano Letters, 10, 2105-2110. https://doi.org/10.1021/nl100614p

[12] Liu, N., Mukherjee, S., Bao, K., Brown, L.V., Dorfmüller, J., Nordlander, P. and Halas, N.J. (2011) Magnetic Plasmon Formation and Propagation in Artificial Aromatic Molecules. Nano Letters, 12, 364-369. https://doi.org/10.1021/nl203641z

[13] Kuzyk, A., Schreiber, R., Fan, Z., Pardatscher, G., Rolle, E.M., Högele, A., Simmel, F.C., Govorov, A.O. and Liedl, T. (2012) DNA-Based Self-Assembly of Chiral Plasmonic Nanostructures with Tailored Optical Response. Nature, 483, 311-314. https://doi.org/10.1038/nature10889

[14] Guerrero, M.A., Augié, B., Alonso, G.J.L., Dzolic, Z., Gómez G.S., Zinic, M., Cid, M.M. and Liz-Marzán, L.M. (2011) Intense Optical Activity from Three-Dimensional Chiral Ordering of Plasmonic Nanoantennas. Angewandte Chemie International Edition, 50, 5499-5503. https://doi.org/10.1002/anie.201007536

[15] Auguié, B., Alonso, G.J.L., Guerrero, M.A. and Liz-Marzán, L.M. (2011) Fingers Crossed: Optical Activity of a Chiral Dimer of Plasmonic Nanorods. Journal of Physical Chemistry Letters, 2, 846-851. https://doi.org/10.1021/jz200279x

[16] Wang, R.Y., Wang, H., Wu, X., Ji, Y., Wang, P., Qu, Y. and Chung, T.S. (2011) Chiral Assembly of Gold Nanorods with Collective Plasmonic Circular Dichroism Response. Soft Matter, 7, 8370-8375. https://doi.org/10.1039/c1sm05590a

[17] Colleen, M.A., Mathew, M.M. and James, C.D. (2011) DNA-Capped Nanoparticles Designed for Doxorubicin Drug Delivery. Chemical Communications, 47, 3418 3420. https://doi.org/10.1039/c0cc04916f

[18] Ben-Moshe A., Maoz, B.M., Govorov A.O. and Markovich, G. (2013) Chirality and Chiroptical Effects in Inorganic Nanocrystal Systems with Plasmon and Exciton Resonances. Chemical Society Reviews, 42, 7028-7041. https://doi.org/10.1039/c3cs60139k

[19] Govorov, A.O. and Fan, Z. (2012) Theory of Chiral Plasmonic Nanostructures Comprising Metal Nanocrystals and Chiral Molecular Media. ChemPhysChem, 13, 2551-2560. https://doi.org/10.1002/cphc.201100958

[20] Govorov, A.O., Fan, Z., Hernandez, P., Slocik, J.M. and Nail, R.R. (2010) Theory of Circular Dichroism of Nanomaterials Comprising Chiral Molecules and Nanocrystals: Plasmon Enhancement, Dipole Interactions, and Dielectric Effects. Nano Letters, 10, 1374-1382. https://doi.org/10.1021/nl100010v

[21] Barron, L.D. and Buckingham, A.D. (2001) Time Reversal and Molecular Properties. Accounts of Chemical Research, 34,781-789. https://doi.org/10.1021/ar0100576

[22] Noguez, C. and Garzon, I.L. (2009) Optically Active Metal Nanoparticles. Chemical Society Reviews, 38, 757-771. https://doi.org/10.1039/b800404h

[23] Roy, S. and Pericas, M.A. (2009) Functionalized Nanoparticles as Catalysts for Enantioselective Processes. Organic \& Biomolecular Chemistry, 7, 2669-2677. https://doi.org/10.1039/b903921j

[24] Tatiana, P., Elvis, C.M. and Ting, I.P. (2014) Chiral Effects in Amino Acid Adsorption on $\mathrm{Au}(111)$ : A Comparison of Cysteine, Homocysteine and Methionine. Surface Science, 629, 20-27. https://doi.org/10.1016/j.susc.2014.01.018

[25] Chapman, C.R.L., Ting, E.C.M., Kereszti, A. and Paci, I. (2013) Self-Assembly of Cysteine Dimers at the Gold Surface: A Computational Study of Competing Interactions. The Journal of Physical Chemistry C, 117, 19426-19435. 
https://doi.org/10.1021/jp405478n

[26] Park, J.W. and Jennifer S. (2014) Structural Study of Citrate Layers on Gold Nanoparticles: Role of Intermolecular Interactions in Stabilizing Nanoparticles. Journal of the American Chemical Society, 136, 1907-1921. https://doi.org/10.1021/ja4097384

[27] Akitsu, T., Uchida, N., Aritake, Y. and Yamaguchi, J. (2008) Induced d-d Bands in CD Spectra Due to Chiral Transfer from Chiral Nickel(II) Complexes to Achiral Copper(II) Complexes and Application for Structural Estimation. Trends in Inorganic Chemistry, 10, 41-49.

[28] Akitsu, T. and Uchida, N. (2010) Induced d-d Bands in CD Spectra of Solution of Chiral Schiff Base Nickel(II) Complex and Ferrocene. Asian Chemistry Letters, 14, 21-28.

[29] Akitsu, T., Yamaguchi, J., Uchida, N. and Aritake, Y. (2009) The Studies of Conditions for Inducing Chirality to $\mathrm{Cu}$ (II) Complexes by Chiral $\mathrm{Zn}$ (II) and $\mathrm{Ni}$ (II) Complexes with Schiff Base. Research Letters in Materials Science, 2009, Article ID: 484172. https://doi.org/10.1155/2009/484172

[30] Akitsu, T., Yamaguchi, J., Aritake, Y., Hiratsuka, T. and Uchida, N. (2010) Observation of Enhanced CD Bands of Metal Complexes, Metallodendrimers, and Metal Clusters by Chiral Schiff Base Metal Complexes. International Journal of Current Research, 1, 1-6.

[31] Akitsu, T., Aritake, Y., Nakayama, T. and Nishizuru, H. (2011) Observation of Induced CD on CdSe Nano-Particles from Chiral Schiff Base Ni(II), Cu(II), Zn(II) Complexes. Inorganic Chemistry Communications, 14, 423-425. https://doi.org/10.1016/j.inoche.2010.12.017

[32] Yamaguchi, J. and Akitsu, T. (2011) Molecular Recognition of Chiral Schiff Base Metal Complexes for Induced CD Bands to Metallodendrimers. International Journal of Current Research, 2, 165-172.

[33] Kominato, C. and Akitsu, T. (2012) Computational Study on UV-Vis and CD Spectra of Chiral Schiff Base Ni(II), Cu(II), and Zn(II) Complexes for Discussion of Induced CD. Journal of Chemistry and Chemical Engineering,, 6, 199-208.

[34] Akitsu, T. and Kominato, C. (2013) Molecular Recognition of Trans-Chiral Schiff Base Metal Complexes for Induced CD. An Integrated View of the Molecular Recognition and Toxinology-From Analytical Procedures to Biomedical Applications, InTech, Rijeka, 515-532. https://doi.org/10.5772/52226

[35] Kimura, N., Nishizuru, H., Aritake, Y. and Akitsu, T. (2013) Observation of Reciprocal Induced CD between Colloidal Gold Nanoparticles and Chiral Schiff Base $\mathrm{Zn}$ (II) Complexes with Parallel Dipole Moments. Journal of Chemistry and Chemical Engineering, 7, 390-394.

[36] Hiratsuka, T., Shibata, H. and Akitsu, T. (2012) Structures and Properties of 3d-4f and 3d Chiral Schiff Base Complexes. Nova Science Publishers, New York, 45-64.

[37] Pooyan, M., Abolfazl, G., Mahdi, B. and Hadi, A. (2013) Tetradentate $\mathrm{N}_{2} \mathrm{O}_{2}$ Type Nickel(II) Schiff Base Complexes Derived from Meso-1,2-diphenyle-1,2-ethylenediamine: Synthesis, Characterization, Crystal Structures, Electrochemistry, and Catalytic Studies. Journal of Coordination Chemistry, 66, 4255-4267.

https://doi.org/10.1080/00958972.2013.867031

[38] Kusum, K.B., Galla, V.K. and Kommuru, G. (2013) Enantioselective Henry Reaction Catalyzed by "Ship in a Bottle" Complexes. Inorganic Chemistry, 52, 8017-8029. https://doi.org/10.1021/ic400599c

[39] Frisch, M.J., Trucks, G.W., Schlegel, H.B., Scuseria, G.E., Robb, M.A., Cheeseman, 
J.R., Scalmani, G., Barone, V., Mennucci, B., Petersson, G.A., Nakatsuji, H., Caricato, M., Li, X., Hratchian, H.P., Izmaylov, A.F., Bloino, J., Zheng, G., Sonnenberg, J.L., Hada, M., Ehara, M., Toyota, K., Fukuda, R., Hasegawa, J., Ishida, M., Nakajima, T., Honda, Y., Kitao, O., Nakai, H., Vreven, T., Montgomery Jr., J.A., Peralta, J.E., Ogliaro, F., Bearpark, M., Heyd, J.J., Brothers, E., Kudin, K.N., Staroverov, V.N., Kobayashi, R., Normand, J., Raghavachari, K., Rendell, A., Burant, J.C., Iyengar, S.S., Tomasi, J., Cossi, M., Rega, N., Millam, J.M., Klene, M., Knox, J.E., Cross, J.B., Bakken, V., Adamo, C., Jaramillo, J., Gomperts, R., Stratmann, R.E., Yazyev, O., Austin, A.J., Cammi, R., Pomelli, C., Ochterski, J., Martin, R.L., Morokuma, K., Zakrzewski, V.G., Voth, G.A., Salvador, P., Dannenberg, J.J., Dapprich, S., Daniels, A.D., Farkas, O., Foresman, J.B., Ortiz, J.V., Cioslowski, J. and Fox, D.J. (2009) GAUSSIAN 09 (Revision A.1). Gaussian, Inc., Wallingford, CT.

[40] Rietveld, H.M. (1969) A Profile Refinement Method for Nuclear and Magnetic Structures. Journal of Applied Crystallography, 2, 65-71. https://doi.org/10.1107/S0021889869006558

[41] Sheldrick, G.M. (2008) A Short History of SHELX. Acta Crystallographica, A64. 112-122. https://doi.org/10.1107/S0108767307043930

[42] Teranishi, T. and Kanehara, M. (2008) Strategy to Fabricate Small Gold Nanoparticle Superlattices and Application to Nanoelectronic Device. The Journal of the Vacuum Society of Japan, 51, 731-736. 


\section{Appendix A. Supplementary Data}

CCDC 1480602 and 1480604 contains the supplementary crystallographic data for $\mathbf{2} \mathbf{c}$ and $\mathbf{3}$ respectively. These data can be obtained free of charge via http://www.ccdc.cam.ac.uk/conts/retrieving.html, or from the Cambridge Crystallographic Data Centre, 12 Union Road, Cambridge CB21EZ, UK; fax: $(+44)$ 1223-336-033; or e-mail: deposit@ccdc.cam.ac.uk.

\section{Supplementary File}

\subsection{XPS}

The XPS measurement was performed in the gold substrate and complexes. This was confirmed the presence or absence of elements of gold substrate surface in order to examine the state of the adsorption of gold and complex in detail as a model case of gold colloid and complex solution.

\subsubsection{Preparation of XPS Measurements}

We performed XPS measurement for $1 \mathrm{a}, \mathbf{1 b}, \mathbf{1 c}, \mathbf{3}$ and $\mathbf{4}$. First we prepared 10 $\mathrm{nm} \times 10 \mathrm{~nm}$ square gold substrate, then prepared $0.01 \mathrm{mM}$ methanol solution of compound $1 \mathrm{a}, 1 \mathrm{~b}$ and $1 \mathrm{c}$, also prepared $0.2 \mathrm{mM}$ methanol solution of $\mathbf{3}$ and $\mathbf{4}$, respectively. The gold substrate put into sample tubes and tried interactions gold surface and complexes by immersing 1 hour complexes solution. Immersed gold substrate washed for three times with chloroform, and then dry surface with $\mathrm{Ar}$ gas. We measured for $\mathrm{Au}, \mathrm{C}, \mathrm{O}, \mathrm{N}$ and Central metal atoms, respectively.

\subsubsection{XPS Qualitative Analysis}

According to XPS measurement, for example, it shows that the constituent elements of the 1a is present in the gold substrate surface. We observe binding energy that $84 \mathrm{eV}$ for Au4f7/2 and $88 \mathrm{eV}$ for Au4f5/2 peaks of the Au substrate elements, and then $285 \mathrm{eV}$ for C1s, $532 \mathrm{eV}$ for O1s, $398 \mathrm{eV}$ for N1s, $853 \mathrm{eV}$ for $\mathrm{Ni} 2 \mathrm{p} 3 / 2$ and $870 \mathrm{eV}$ for Ni2p1/2 peaks of constituent elements of 1a. Copper atom has been measured as a comparison but it should be appreciated that copper atom was not observed matter of course. In the same way, peak of the complex elements (C, O, N and Central metal atoms) also for $1 \mathrm{~b}, 1 \mathrm{c}$ and 4 was observed. Although the $\mathrm{C}, \mathrm{O}$ and $\mathrm{N}$ elements was observed for $\mathbf{3}$, the central metal has not been observed. This point will be discussed in conjunction with the STM. The supporting information shows the results of $1 \mathrm{~b}, 1 \mathrm{c}, 3$ and 4 .

\subsubsection{XPS Quantitative Analysis}

We performed a quantitative analysis of elements by the area calculation for XPS spectrum of previous chapter. Results are shown Table 1.

Configuration element ratio Nitrogen and the center metal of the complexes is matched from the calculation results. Induced CD compounds is present on gold substrate with keeping its shape. Then, we calculated the percentage of nitrogen and central metal of the complexes on the basis of Table 1 . The ratio of nitrogen and central metal in Au surface is 2:0.82(1a), 2:0.81 (1b), 2:1.28 (1c).This results 
is almost the same as the ratio of the elements of these compound. For 3, nitrogen and central metal is present on Au surface but about 4, the nitrogen is present but the central metal was not observed on the Au surface. We can say the presence or absence of the induced $\mathrm{CD}$ is, is that consistent with the presence or absence of the central metal by XPS spectra in this chapter.

\subsection{STM}

STM measurement was performed to investigate the adsorption structure of the gold substrate and the complex visually.

\subsubsection{Preparation of STM Measurements}

We performed STM measurement for $1 \mathrm{a}, 1 \mathrm{~b}, 1 \mathrm{c}, 3$ and 4 . First we prepared 10 $\mathrm{nm} \times 10 \mathrm{~nm}$ square gold substrate, then prepared $0.01 \mathrm{mM}$ methanol solution of $1 \mathrm{a}, \mathbf{1 b}$ and $1 \mathrm{c}$, also prepared $0.2 \mathrm{mM}$ methanol solution of $\mathbf{3}$ and $\mathbf{4}$, respectively. It was performed exima treatment $(172 \mathrm{~nm})$ for 3 minutes for activating the $\mathrm{Au}$ surface. The gold substrate put into sample tubes and tried interactions Au surface and complexes by immersing 1 hour complexes solution. Immersed gold substrate washed for three times with chloroform, and then dry surface with Ar gas.

\subsubsection{Measurements of STM}

In Figure S1, it can be observed gold atom one by one. The distance between atoms is consistent with $0.24 \mathrm{~nm}$ is a literature value of gold [42].

In Figure S2, surface of $\mathrm{Au}$ and $1 \mathrm{a}$ can be observed layered structure on the left, also the structure of the particulate on the right can be observed. Figure S3 is the same sample as Figure S2 but a different location. We performed the analysis of the depth about where was surrounded by a square (Figure S4).

The grain height is $1.194 \mathrm{~nm}$ and it is that substantially coincide with the longitudinal length of $1 \mathrm{a}(1.266 \mathrm{~nm})$. From this it can be said that the complex is adsorbed standing on the Au surface. This fact is consistent with the theoretical study [20].

In Figure S5, surface of $\mathrm{Au}$ and $\mathbf{3}$ can be observed layered structure on the right, also the structure of the particulate on the left can be observed. Granular structure on the left we consider to be a structure derived from the same complex as in the case of 1a. However, in the XPS spectra, the central metal of the

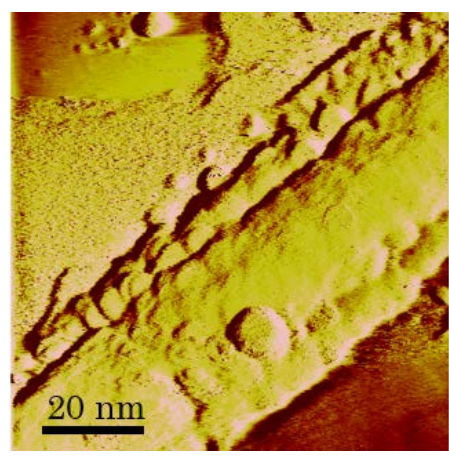

Figure S1. STM image of $50 \mathrm{~nm} \times 50 \mathrm{~nm}$ square Au substrate (maximum roughness was less than $1 \mathrm{~nm}$ ). 


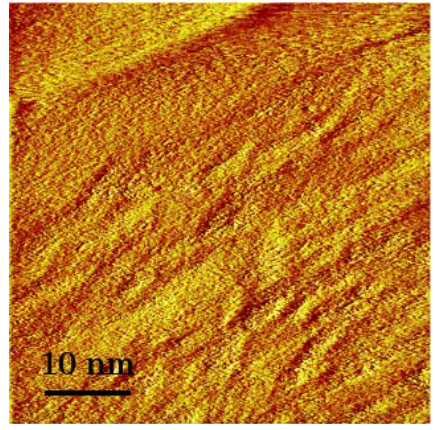

Figure S2. STM image of $100 \mathrm{~nm} \times 100 \mathrm{~nm}$ square $\mathrm{Au}$ and 1a substrate (1).

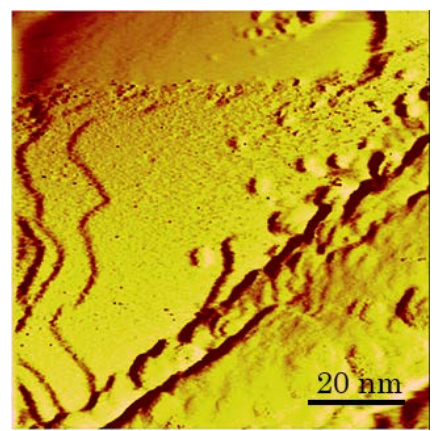

Figure S3. STM image of $100 \mathrm{~nm} \times 100 \mathrm{~nm}$ square Au and 1a substrate (2).
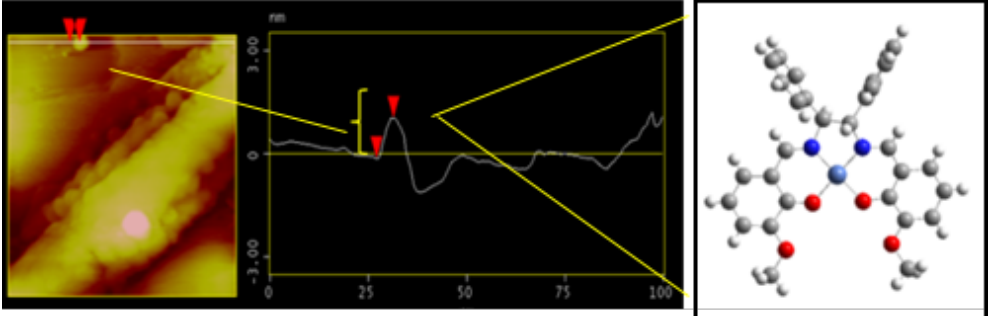

Figure S4. Depth analysis and optimized structure of 1a.

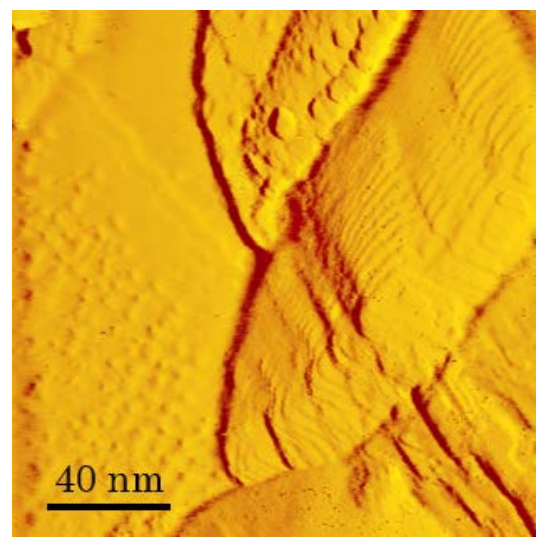

Figure S5. STM image of $200 \mathrm{~nm} \times 200 \mathrm{~nm}$ square Au and 3 substrate.

complex did not exist. We considered compound exist in the Au surface in the state of the ligand that compound has no central metal. This complex is induced $\mathrm{CD}$ was not observed but it is that this is one of cause. 
Submit or recommend next manuscript to SCIRP and we will provide best service for you:

Accepting pre-submission inquiries through Email, Facebook, LinkedIn, Twitter, etc. A wide selection of journals (inclusive of 9 subjects, more than 200 journals)

Providing 24-hour high-quality service

User-friendly online submission system

Fair and swift peer-review system

Efficient typesetting and proofreading procedure

Display of the result of downloads and visits, as well as the number of cited articles Maximum dissemination of your research work

Submit your manuscript at: http://papersubmission.scirp.org/

Or contact ijoc@scirp.org 